\title{
e-Interview
}

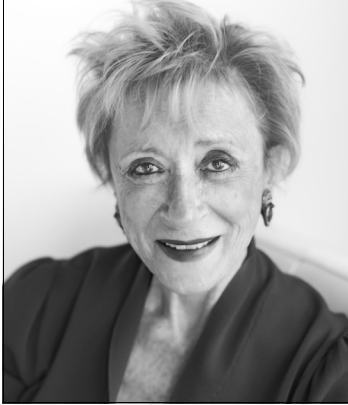

Photo (C) Dan Welldon

\section{Dr Estela Welldon}

Estela Welldon is Honorary Consultant Psychiatrist in Psychotherapy at the Portman Clinic and Honorary Elected Life President of the International Association for Forensic Psychotherapy. She trained in medicine in Mendoza, Argentina, and then in psychiatry at Menninger School of Psychiatry, Topeka, Kansas, USA. She has a specialist interest in the use of psychodynamic psychotherapy with perversions, violence and criminality, as well as in forensic psychotherapy.

\section{If you were not a psychiatrist, what would} you do?

I would love to be a great operatic conductor, such as Antonio Pappano, our own Director of the Royal Opera House.

\section{Do you feel stigmatised by your profession?}

Only once. In an American group psychoanalytic annual pre-conference devoted to the understanding of sexual disorders, I was left in complete isolation as soon as my colleagues got to know that I was treating perpetrators of sexual abuse.

What are your interests outside of work? I am addicted to opera and music and art in general. I firmly believe that life would be meaningless without music

\section{What question would you choose to ask yourself?}

'What is the professional achievement you are most proud of?' - The foundation in 1991 of the International Association for Forensic Psychotherapy, an umbrella organisation which provides different forums for multiprofessionals to get together and to share inherent difficulties we are daily challenged with.

Who was your most influential trainer, and why?

My first psychoanalyst Dr Etchegoyen in Argentina, from whom I have learnt much then and even more later on in life. He was an exemplary person with almost visionary qualities. He provided me with my first insights and awareness about unconscious motivations to be used in being a true professional and a generous friend with colleagues.

What job gave you the most useful training experience?

My time at the Henderson, Surrey, the first therapeutic community created by Maxwell Jones. This place was really and genuinely created for the patients' welfare, and not just for the staff. The principles of democracy and social justice were crucial for the patients gaining a sense of self-respect and dignity, perhaps for the first time in their lives, which were essential in acquisition of thinking that led to verbal communication and cessation of antisocial behaviour.

\section{Which publication has influenced you} most?

The Death of Ivan Ilyich by Tolstoy demonstrates in a very eloquent way the importance of living a true life without self-deception.

\section{How has the political environment influenced your work?}

A great deal, since I believe that the great divisions of 'the haves' and the 'have-nots' are at the root of most antisocial activities. Our work in forensic psychotherapy focuses not only on the patient and the professional but also importantly on society, represented by the criminal justice system. Hence education of politicians and the media has an important place and I believe their contribution to our field is vital for our own growth and development. Incidentally, the theme of our next 21st Annual International Conference is 'Corruption, deception and collusion: attacks on the mind' - and as main speakers among other professionals will be politicians, journalists and authors. This will take place in March 2013 in Venice, Italy.

\section{What part of your work gives you the most satisfaction?}

This could be divided into different developments of our therapeutic work since our patient population is not only a most disturbed one but also the one with most terrible backgrounds of deprivation. As therapists we have to work through a lot of unexpressed anger, often suppressed over many years and it is of great satisfaction to receive acknowledgments from those same patients of the great changes they have been able to achieve thanks to their being able to express their awful feelings of distrust, cruelty, etc.

\section{What do you least enjoy?}

The creation of managers in our profession. The push towards quantity seems to be ignorant of the time required for highquality treatment. Managers are, sadly, not aware that patients with personality disorder can only respond to long-term analytic therapy and that by cutting down ong-term analytic therapy they are jeopardising the patients' improvement and actually creating disruptive situations which those patients will cope with using their only known effective tool - acting in antisocial ways, disrupting society for their own lack of understanding. I also wonder why, with managers, there is no evidence that they are held to account for their performance, as doctors are, and why they are never the first victims of cuts or 'cost improvements' as they are now known.

\section{What is the most important advice you} could offer to a new trainee?

I would emphasise that psychiatry and especially forensic psychotherapy has important links with all arts, especially opera and literature. Understanding 'bizarre' behaviour of human beings through the arts is an effective way to integrate psychodynamic understanding exempt of prejudice necessary for the proper treatment of the offender patient. We have to see the patient in his/her totality and not just the offence.

\section{Do you think psychiatry is brainless or} mindless?

I think it is very interesting when people talk of psychiatrists as 'shrinks' - our aim is exactly the opposite, to open up and expand minds.

What single change to mental health legislation would you like to see? The requirement for availability of 'appropriate treatment' under the amended Mental Health Act (which may be neither accepted by the patient nor efficacious) needs to be more clearly defined. This will avoid psychiatrists having to detain patients who are unlikely to respond to treatment (and who disrupt the treatment of those who are likely to) or discharge patients at high risk for whom the psychiatrist will be held responsible, yet over whom they have no control.

What single area of psychiatric practice is most in need of development?

The impact of uncertain funding and shortterm thinking on personality disorder services. This patient group are, arguably, least able to manage uncertainty and inconsistency and yet the survival of their services is often dictated by the media and political whim rather than identified need.

Dominic Fannon

doi: 10.1192/pb.bp.112.038869 